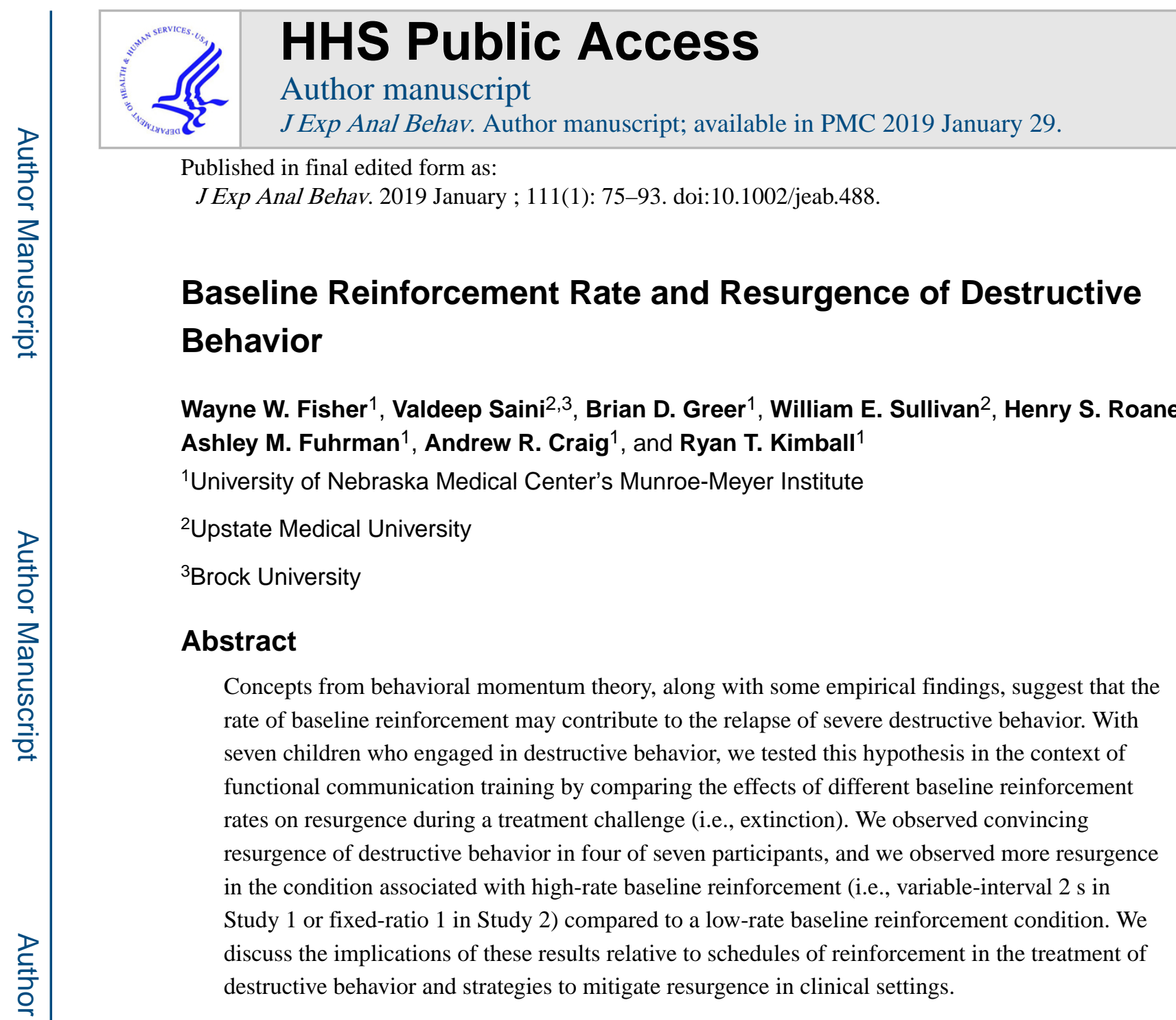

\title{
Keywords
}

behavioral momentum theory; functional communication training; reinforcement rate; treatment relapse; resurgence

\begin{abstract}
A large body of research in applied behavior analysis has been dedicated to the assessment and treatment of severe behavior disorders exhibited by individuals with intellectual disabilities and/or autism spectrum disorders (Beavers, Iwata, \& Lerman, 2013). Behavior analysts identify the environmental variables responsible for the maintenance of destructive behavior using functional analysis (FA) methodology (Iwata, Dorsey, Slifer, Bauman, \& Richman, 1982/1994). An FA is an effective assessment tool used to identify the function(s) of behavior by systematically manipulating environmental events and providing predetermined consequences contingent on the target, problematic response (e.g., delivering the consequence on a fixed-ratio [FR] 1 schedule; Betz, Fisher, \& Saini, in press; Hanley, Iwata, $\&$ McCord, 2003). Levels of destructive behavior in the test condition for a given
\end{abstract}

Address correspondence to Valdeep Saini (vsaini@brocku.ca), Department of Applied Disability Studies, Brock University, 1812 Sir Isaac Brock Way, St. Catherines, ON, Canada. 
reinforcement contingency are then compared to those in a condition that lacks the relevant antecedent and consequent events being tested, known as the control condition.

A common intervention for the treatment of destructive behavior based on the results of an FA is functional communication training (FCT), which involves (a) teaching the individual to request the maintaining reinforcer for destructive behavior using an appropriate communication response (e.g., saying "my turn" to gain access to tangible items) and (b) discontinuing reinforcement for destructive behavior (i.e., extinction). Research indicates that function-based interventions, like FCT, typically reduce destructive behavior by at least 90\% and are more effective than other behavioral treatments that are not informed by a FA (Didden, Duker, \& Korzilius, 1997; Didden, Korzilius, van Oorsouw, \& Sturmey, 2006; Greer, Fisher, Saini, Owen, \& Jones, 2016; Iwata, Pace, et al., 1994; Rooker, Jessel, Kurtz, \& Hagopian, 2013).

Reinforcement-schedule thinning has been an effective method for decreasing the overall rate of reinforcement for appropriate behavior while maintaining low levels of destructive behavior during FCT (Greer et al., 2016). However, in some cases, discontinuing FCT or rapidly thinning the schedule of alternative reinforcement during FCT can result in the recurrence of destructive behavior (e.g., Briggs, Fisher, Greer, \& Kimball, 2018; Lieving, Hagopian, Long, \& O’Connor, 2004; Volkert, Lerman, Call, \& Trosclair-Lasserre, 2009; Wacker et al., 2011). The recurrence of destructive behavior following treatment with FCT is considered a form of treatment relapse and has important implications for the longevity of treatment effects (Mace \& Nevin, 2017; Podlesnik \& Kelley, 2015; Pritchard, Hoerger, \& Mace, 2014). One type of relapse that is highly relevant for interventions based on differential reinforcement of alternative behavior (DRA), such as FCT, is resurgence, which occurs when the alternative response (e.g., the functional communication response [FCR]) contacts extinction (Wacker et al., 2013). In part because of its relevance for clinical applications of FCT, resurgence has been studied extensively in basic- and translationalresearch settings (e.g., Nevin et al., 2016; Podlesnik \& Kelley, 2014; Podlesnik \& Shahan, 2009; Shahan \& Craig, 2017; Shahan \& Sweeney, 2011; Sweeney \& Shahan, 2013; Winterbauer \& Bouton, 2010).

In animal-laboratory research, resurgence is typically studied in three phases (Lattal \& St. Peter Pipkin, 2009). First, a target response (e.g., a lever press) is reinforced on some prearranged schedule, usually a variable-interval (VI) schedule, because VI schedules control the programmed rate of reinforcement better than other schedules (Nevin \& Baum, 1980). Next, the target response is placed on extinction, and an alternative response (e.g., a nose poke into an illuminated aperture) is reinforced, again, typically using a VI schedule. In the final phase, the alternative response also is placed on extinction. If the target response increases in the final phase, it is said to resurge (Doughty \& Oken, 2008; Lieving \& Lattal, 2003; Podlesnik \& Shahan, 2009). This three-phase resurgence paradigm has strong parallels to the treatment of destructive behavior, and the final extinction phase models a treatment challenge (i.e., a series of omission errors) that might reasonably occur when caregivers implement FCT (Greer, Fisher, Romani, \& Saini, 2016; Wacker et al., 2013). For example, a child might use an FCR to request caregiver attention while the caregiver is on the phone. In this situation, when the caregiver is unable to provide the reinforcer, the FCR 
is exposed to a local period of extinction, which may produce the resurgence of destructive behavior.

An important finding from basic research on resurgence is that rates of reinforcement for target and alternative behavior are variables that contribute to resurgence, with higher rates of reinforcement generally producing greater resurgence (Cançado, Abreu-Rodrigues, \& Aló, 2015; Leitenberg, Rawson, \& Mulick, 1975; Podlesnik \& Shahan, 2009; Pritchard, Hoerger, Mace, Penney, \& Harris, 2014, Winterbauer \& Bouton, 2012; but see Craig \& Shahan, 2016a for exceptions). These findings are generally consistent with the predictions of behavioral momentum theory (BMT; Craig, Nevin, \& Odum, 2014). From a BMT perspective, higher rates of reinforcement in a given stimulus context add to a mass-like property of the response via a Pavlovian process produced through stimulus-reinforcer pairings between reinforcers and the prevailing context, thus promoting response persistence and resurgence (Shahan \& Sweeney, 2011). Response persistence and resurgence is thus affected by both baseline reinforcement (historically delivered in that context), as well as reinforcement currently arranged for the alternative response (Greer, Fisher, Romani, et al., 2016; Nevin \& Shahan, 2011; Shahan \& Sweeney, 2011), with the majority of studies examining the effects of high and low rates of alternative reinforcement on subsequent resurgence (e.g., Fujimaki, Lattal, \& Sakagami, 2015; Podlesnik \& Shahan, 2009; Sweeney $\&$ Shahan, 2013). Given that higher rates of reinforcement produce increased stimulusreinforcer pairings, the introduction of a disruptor (e.g., extinction) for the alternative response is likely to produce more resurgence of the target response than a lower rate of reinforcement and fewer stimulus-reinforcer pairings.

Behavioral momentum theory predicts that higher rates of reinforcement for destructive behavior during baseline will lead to greater resurgence during a subsequent extinction challenge than lower rates of reinforcement during baseline (Nevin \& Shahan, 2011). A number of applied investigations of resurgence using children who engage in severe destructive behavior as participants have shown this to be accurate when comparing highand low-rate VI schedules (Mace et al., 2010; Nevin et al., 2016; Pritchard et al., 2016; Pritchard, Hoerger, Mace, Penney et al., 2014). For example, Fisher, Greer, Fuhrman, Saini, and Simmons (in press) recently showed that lower rates of baseline reinforcement resulted in less resurgence than higher rates of baseline reinforcement (see also Fisher et al., 2018). However, one limitation of previous applied investigations (e.g., Fisher et al., in press) is that the baseline reinforcement comparisons often are combined with other procedural variations that likely affect the level of resurgence (e.g., higher vs. lower rates of reinforcement for the FCR; longer vs. shorter exposure to periods of extinction plus alternative reinforcement). An additional characteristic of the Fisher et al. (in press) study that may limit its clinical generalizability was that the experimenters used VI schedules, whereas in most clinical studies evaluating the effects of FCT, destructive behavior is initially reinforced on an FR 1 schedule (e.g., Fisher et al., 1993; Hanley, Iwata, \& Thompson, 2001).

The purpose of the current pair of studies was to isolate the effects of high and low rates of baseline reinforcement on the resurgence of destructive behavior following FCT. In Study 1, we compared high- and low-rate reinforcement for destructive behavior during baseline on resurgence following FCT using a two-condition multielement design. We arranged 
differential rates of baseline reinforcement in a manner consistent with prior basic research studies on this topic by programming a dense-VI schedule in one condition and a lean-VI schedule in the other. During FCT, the FCR produced the same rate of VI reinforcement for the same number of treatment sessions in both conditions (unlike the study by Fisher et al., in press). In Study 2, we used an FR 1 schedule in the high-rate reinforcement condition to model what typically occurs when clinicians treat destructive behavior and compared that to a VI baseline in the low-rate reinforcement condition. During FCT, both conditions produced the functional reinforcer on an FR 1 schedule to mimic how FCT is commonly implemented during intervention, unlike previous translational investigations of resurgence that programmed VI schedules for the FCR (see Volkert et al., 2009 for a notable exception). In both studies, we compared levels of destructive behavior during a phase in which we arranged extinction for the FCR, thereby modeling a treatment challenge analogous to situations in which a caregiver cannot deliver reinforcement for the FCR in the natural environment. If, as BMT predicts, higher rates of baseline reinforcement result in greater resurgence when an FCR contacts extinction, then this finding could have important implications for how clinicians should program baseline rates of reinforcement for destructive behavior when evaluating DRA treatments like FCT. Specifically, it would suggest that high-rate reinforcement conditions for destructive behavior, similar to those arranged in typical FA baselines, might be clinically contraindicated (because it might produce behavior that is especially susceptible to relapse).

\section{General Method}

\section{Subjects and Setting}

Seven children referred for the assessment and treatment of aggressive, disruptive, and/or self-injurious behavior (SIB) participated (pseudonyms are used for all children). Marcus, Ace, Bernie, and Owen participated in Study 1, and Harvey, Ryan, and Tamra participated in Study 2. All participants were diagnosed with an autism spectrum disorder and their ages ranged from 4 to 11 years old ( $M=7.4$ years). Participants communicated through augmentative communication, gestures, or one- to three-word vocal utterances.

Sessions for all participants except Tamra took place in $3 \mathrm{~m}$ by $3 \mathrm{~m}$ therapy rooms equipped with an intercom system and a one-way observation panel. Session rooms contained padding on the walls and floors to minimize the risk of injury associated with destructive behavior. Sessions for Tamra took place in $8 \mathrm{~m}$ by $8 \mathrm{~m}$ classrooms. Furniture (e.g., table, chairs) was present in session rooms for all participants except Ace due to the risk of injury associated with a topography of his disruptive behavior (i.e., throwing furniture). Relevant session materials also were present (described below).

\section{Response Measurement and Interobserver Agreement}

Observers collected data on laptop computers. The primary dependent variables were responses per minute of SIB, aggression, disruptions, and FCRs. Self-injurious behavior included self-biting, body slamming, self-hitting, self-scratching, nose gouging, and head banging. Aggression included hitting, kicking, pushing, pinching, scratching, and throwing objects at the therapist. Disruptions included hitting, kicking, or throwing objects, tearing 
clothing, and swiping materials off of and overturning furniture. Functional communication responses were defined as the participant exchanging (Marcus, Ace, and Owen) or touching (Bernie, Ryan, and Tamra) an FCR card or emitting a vocal FCR (Harvey). In addition to the primary dependent variables, we also collected data on the number of reinforcer deliveries to monitor the rate of reinforcement across the two contexts. Doing so allowed us to compare high and low rates of baseline reinforcement in a manner consistent with previous research (e.g., Fisher et al., in press; Fuhrman, Fisher, \& Greer, 2016; Podlesnik \& Shahan, 2009).

For a portion of the sessions, an independent second observer collected data simultaneously with the primary data collector. Sessions were divided into 10-s intervals, and an agreement was recorded for each interval in which both observers measured the same number of responses (i.e., exact agreement within the interval). We summed the number of agreement intervals and then divided the number of agreement intervals by the total number of intervals within the session. Each quotient was then converted to a percentage. During Study 1, we collected interobserver agreement (IOA) for $38.1 \%, 25 \%, 53.6 \%$, and $36.1 \%$ of sessions for Marcus, Ace, Bernie, and Owen, respectively. Mean IOA was $99.1 \%$ (range, $90 \%$ to $100 \%$ ) for Marcus, $98.5 \%$ (range, $83.3 \%$ to $100 \%$ ) for Ace, $98.7 \%$ (range, $75 \%$ to $100 \%$ ) for Bernie, and $96.7 \%$ (range, $63.3 \%$ to 100\%) for Owen. During Study 2, we collected IOA for $50 \%, 43.7 \%$, and $36.1 \%$ of sessions for Harvey, Ryan, and Tamra, respectively. Mean IOA was $95.3 \%$ (range, $89.5 \%$ to $99.2 \%$ ) for Harvey, $93.1 \%$ (range, $88.3 \%$ to $97 \%$ ) for Ryan, and $89.1 \%$ (range, $80 \%$ to $98.8 \%$ ) for Tamra.

\section{Pre-Experimental Analyses}

Functional analysis (not shown).-We conducted an FA of each participant's destructive behavior to identify its maintaining variables (data available upon request). We used either a multielement design or a sequential test-control pairwise design (Iwata, Duncan, Zarcone, Lerman, \& Shore, 1994) with procedures similar to those described by Iwata, Dorsey, et al. (1982/1994). During Study 1, with the exception of Marcus, a series of ignore sessions preceded the multielement or pairwise design to screen for automatically reinforced destructive behavior (Querim et al., 2013). Marcus's FA did not include the series of ignore sessions because the results of an open-ended interview with his caregiver strongly suggested an attention function of his destructive behavior, which we did not want to inadvertently extinguish. For all participants, we also equated the duration of reinforcer access across test conditions (Fisher, Piazza, \& Chiang, 1996). Specific tangible and instructional materials that were included in the FA were derived from stimulus preference assessments (Fisher et al., 1992) and open-ended interviews with caregivers (Hanley, 2012).

Across conditions, putative reinforcers for destructive behavior were delivered for 20 -s at a time following the occurrence of destructive behavior, and doing so eliminated the motivating operation (MO) for destructive behavior. The results of the FA revealed at least one function of destructive behavior for each participant. For Marcus, access to tangible items and escape from instructions reinforced his destructive behavior. Ace's disruptions were maintained by automatic reinforcement, and his aggression and SIB were reinforced by access to tangible items. Destructive behavior for Bernie and Ryan was reinforced by access to tangible items. For Harvey and Tamra, destructive behavior was reinforced by escape 
from instructions. Finally, Owen's SIB was reinforced by escape from social praise. In Study 1, we targeted the tangible function of destructive behavior for Marcus, Ace, and Bernie (i.e., access to preferred toys) and the escape from social praise function of destructive behavior for Owen. In Study 2, we targeted the tangible function of destructive behavior for Ryan and the escape function of destructive behavior for Harvey and Tamra.

FCT pretraining (not shown).-We taught participants to engage in the FCR prior to the initiation of baseline (Study 1) or following baseline but prior to the FCT phase (Study 2). During pretraining, therapists placed destructive behavior on extinction and used a progressive-prompt delay (i.e., $0 \mathrm{~s}, 2 \mathrm{~s}, 5 \mathrm{~s}$, and $10 \mathrm{~s}$ delay to physical guidance; Charlop, Shreibman, \& Thibodeau, 1985) to teach participants to engage in the FCR to gain access to the functional reinforcer. There was a 3 -s changeover delay (COD; Herrnstein, 1961) in place to prevent adventitiously reinforcing chains of destructive behavior and the FCR. Thus, if destructive behavior occurred within $3 \mathrm{~s}$ of the FCR, therapists required a new FCR that did not co-occur with destructive behavior before providing the functional reinforcer. Therapists terminated pretraining following at least two consecutive sessions with low levels of destructive behavior and high levels of independent FCRs (e.g., 80\% or greater). We introduced pretraining before baseline to ensure that FCT would be an appropriate treatment approach for each participant's socially maintained destructive behavior. Note that this experimental sequence slightly differs from the typical resurgence arrangement (e.g., Lattal \& St. Peter Pipkin, 2009).

\title{
Study 1: Translational Evaluation of Baseline Reinforcement Rate on Resurgence
}

The purpose of Study 1 was to conduct a translational evaluation of the effects of dense versus lean VI schedules during baseline on the resurgence of destructive behavior. Similar to Fisher et al. (in press), we used a three-phase resurgence arrangement with an embedded multielement design in which we programmed two different contexts. We programmed unique condition-correlated stimuli (e.g., light filters, shirts) in each context in an attempt to facilitate discrimination between the two contexts (e.g., Conners et al., 2000). For each participant, we randomly selected two colors and assigned them to each context (e.g., blue stimuli in the lean baseline reinforcement context and yellow stimuli in the dense baseline reinforcement context). Phase 1 consisted of baseline, during which the therapists reinforced destructive behavior on either a dense or lean VI schedule. Phase 2 consisted of FCT, during which the therapists placed destructive behavior on extinction and reinforced FCRs on a dense VI schedule. Phase 3 consisted of an extinction challenge, during which there were no programmed consequences for destructive behavior or the FCR. Conditions occurred in a quasi-random order with no more than two sessions of the same condition occurring consecutively.

\section{Procedure}

\author{
Assessments informing baseline reinforcement schedules (data available \\ upon request).-To inform the dense and lean reinforcement schedules employed during \\ baseline, we conducted a progressive-interval assessment (PIA; Findley, 1958) and evaluated
}


the average latency to destructive behavior during the last five baseline sessions of the FCT evaluation for each participant (assessments described below). Whichever value was denser (i.e., the longest interval that did not produce untoward side effects during the PIA or the interval that was just below the average latency to destructive behavior during the last five baseline sessions from the FCT evaluation) informed the dense reinforcement schedule used in baseline. We then multiplied this dense reinforcement schedule by 4.5 to determine the lean reinforcement schedule, thus arranging a greater than fourfold difference between the programmed rates of reinforcement in the dense and lean contexts during baseline (see Fisher et al., in press; Mace et al., 1990; Shahan, Magee, \& Dobberstein, 2003; for similar disparities in reinforcement schedules).

PIA.: We conducted the PIA using procedures similar to those described by Fisher et al. (in press) to determine the longest interval of time that did not produce untoward side effects (i.e., a burst of destructive behavior or negative emotional responding). During the PIA, a therapist exposed the participant to a preset duration of the establishing operation for destructive behavior. The therapist increased the duration of exposure to the establishing operation after two consecutive trials at each of the following fixed-interval (FI) schedules: 2 s, 4 s, 8 s, 10 s, 15 s, 20 s, 30 s, 45 s, 65 s, 90 s, 120 s, 150 s, and $180 \mathrm{~s}$. That is, therapists provided reinforcement (using the putative reinforcer maintaining destructive behavior) for 20-s contingent on the first instance of destructive behavior following the fixed amount of time. Therapists terminated the PIA after the participant (a) completed two trials at the FI 180-s schedule, (b) engaged in three instances of destructive behavior within $5 \mathrm{~s}$, or (c) engaged in $5 \mathrm{~s}$ of continuous crying or negative vocalizations.

Latency analysis.: In addition to the PIA, we also evaluated latency data to help inform the baseline reinforcement schedules. We calculated the latency to destructive behavior after each exposure to the establishing operation during the last five baseline sessions from the FCT evaluation. We then averaged those latencies to destructive behavior across the five sessions and compared that average to the longest interval that did not produce untoward side effects during the PIA. As stated previously, we selected the denser of the two values as the dense reinforcement schedule during baseline. For example, if a burst of destructive behavior occurred at the 4-s interval of the PIA and the average latency to destructive behavior during the last five baseline sessions was $7 \mathrm{~s}$, therapists programmed the dense reinforcement schedule during baseline to be VI 2 s (i.e., the longest interval during the PIA that did not produce untoward side effects).

Reinforcement schedule discrimination assessment.: After identifying the contextspecific baseline reinforcement schedules through the PIA and latency analyses, we evaluated each participant's preference for the baseline contexts using a concurrent-chains preference assessment (see Hanley, Piazza, Fisher, Contrucci, \& Maglieri, 1997; Kodak et al., 2016, for similar procedures). That is, we measured the allocation of choice between two different contexts, each associated with either a dense or lean VI schedule of reinforcement, to test for discrimination of the programmed rates of reinforcement. We predicted to observe a pattern of responding that reflected participants' preference for the dense schedule of reinforcement. 
During the assessment, experimenters first guided the participant's choice towards each baseline context for a minimum of three sessions. Next, we measured preference for the baseline contexts during free-choice sessions. We continued these procedures until we observed the desired pattern of responding (e.g., preference for the context with the dense schedule of reinforcement), and we then programmed the same schedules of reinforcement during baseline unless otherwise noted below. If the participants did not display discriminated responding, we further thinned the schedule of reinforcement in the lean baseline context (described below for Bernie and Owen).

Baseline.-We implemented baseline sessions using procedures identical to those from the relevant test condition from each participant's FA with three exceptions. First, we conducted baseline sessions in two different contexts signaled by unique condition-correlated stimuli (described above). Second, we arranged VI schedules of reinforcement for destructive behavior, the mean intervals for which were identified using the procedures described above (i.e., PIA and latency analysis; see also Fisher et al., in press). Third, these and all subsequent sessions for Marcus, Ace, and Bernie lasted $10 \mathrm{~min}$, and all sessions for Owen lasted $5 \mathrm{~min}$.

We programmed reinforcer deliveries using VI schedules by randomly sampling without replacement from intervals produced by the Fleshler and Hoffman (1962) constant probability distribution. The specific number of sampled intervals depended on (a) the VI schedule programmed; (b) the upcoming session duration; and (c) the duration of the reinforcement interval, which we set at $20 \mathrm{~s}$ for all participants in Study 1. We ensured that efficient responding would continue to produce reinforcement throughout the session but also that reinforcement intervals that could not be attained (even with maximally efficient responding) were not sampled. For example, a VI 2-s schedule for a 10-min session with 20$\mathrm{s}$ reinforcer deliveries resulted in 28 sampled intervals (600-s session / [2-s VI duration +20 s reinforcer delivery]).

At the beginning of each session for Marcus, Bernie, and Owen, we reinforced the first instance of destructive behavior on an FR 1 schedule, but each subsequent instance of destructive behavior produced reinforcement according to the context-specific VI schedule. For Ace, destructive behavior produced reinforcement according to the context-specific VI schedule for the entirety of the session. Functional communication responses (i.e., exchangeable cards) were not present during baseline conditions. We continued baseline for at least five sessions and until the following stability criteria were met in each context: (a) the standard deviation of the response rates during baseline was no more than $50 \%$ of the mean rate of responding; (b) the experimenters determined responding to be steady via visual inspection, or the trend was opposite that of the treatment goal (i.e., an upward trend); and (c) no more than $20 \%$ of the baseline data points were in the range targeted for treatment during FCT.

Dense.: Destructive behavior produced the functional reinforcer according to a dense VI schedule. Based on the analyses described above, we selected a VI 2-s schedule for all participants. 
Lean.: Procedures in this context were identical to those in the dense baseline context except that destructive behavior produced the functional reinforcer according to a lean VI schedule. For all participants, we initially selected the lean VI schedules of reinforcement by multiplying the schedule of reinforcement in the dense baseline context by 4.5. Accordingly, for Marcus, we selected a VI 9-s schedule. For Ace, we introduced a VI 9-s schedule, but initial baseline sessions demonstrated a lack of differentiation between reinforcer deliveries per minute in the VI 2-s (dense reinforcement) and VI 9-s (lean reinforcement) schedules. Therefore, we increased the VI 9-s schedule to a VI 14-s schedule. To arrive at the VI 14-s schedule, we multiplied $9 \mathrm{~s}$ by 1.5 to obtain a product of $13.5 \mathrm{~s}$. We rounded 13.5 up to 14 to set the lean reinforcement schedule at a VI 14-s schedule (see participant Derek, from Fisher et al., in press, for a similar calculation). For Bernie, we selected a VI 90-s schedule. Bernie also did not demonstrate discriminated responding in a schedule-discrimination assessment with a VI 9-s schedule. Consequently, we then assessed for discriminated responding at a VI 14-s schedule (i.e., similar to Ace and Owen) and at a VI 28-s schedule. The VI 28-s schedule was a twofold difference from the VI $14 \mathrm{~s}$, but we continued to observe nondiscriminated responding. Finally, we selected a VI 90-s schedule to increase the likelihood of discriminated responding due to the extreme disparity between a lean VI 90-s schedule and the corresponding, dense VI 2-s schedule. For Owen, we completed the same calculation and selected a VI 14-s schedule because Owen did not display discriminated responding in the schedule-discrimination assessment. In summary, through multiple analyses, we selected the following lean VI schedules of reinforcement: VI $9 \mathrm{~s}$ for Marcus, VI $14 \mathrm{~s}$ for Ace, VI 90 $\mathrm{s}$ for Bernie, and VI $14 \mathrm{~s}$ for Owen.

FCT.-We implemented identical FCT procedures in both contexts. During FCT sessions, we placed all destructive behavior on extinction and reinforced FCRs according to VI schedules of reinforcement. Experimenters did not prompt FCRs during this phase.

For Marcus, Ace, and Bernie, we selected the VI schedule of reinforcement for FCRs by adding the VI values from the dense and lean baseline contexts and then dividing the sum by two. For example, if we programmed a VI $2 \mathrm{~s}$ in the dense baseline context and a VI $9 \mathrm{~s}$ in the lean baseline context, the VI schedule used in both contexts during FCT was a VI $5.5 \mathrm{~s}$. Thus, we selected the following VI schedules during FCT: VI $5.5 \mathrm{~s}$ for Marcus and VI $8 \mathrm{~s}$ for Ace. This calculation resulted in a VI 46-s schedule for Bernie. However, such a schedule might have been too lean to maintain FCRs. Therefore, we doubled the leanest reinforcement schedule used during FCT across participants (VI $8 \mathrm{~s}$ for Ace), which resulted in a VI 16-s schedule for Bernie. For Owen, we used a VI 2-s schedule in both contexts to approximate the schedule of reinforcement that practitioners often program when initiating FCT (i.e., FR 1; Tiger, Hanley, \& Bruzek, 2008). In summary, we programmed the following schedules of reinforcement during FCT: VI $5.5 \mathrm{~s}$ for Marcus, VI $8 \mathrm{~s}$ for Ace, VI $16 \mathrm{~s}$ for Bernie, and VI $2 \mathrm{~s}$ for Owen. Functional communication training ended after two consecutive sessions with at least an $85 \%$ decrease in baseline rates of destructive behavior in both contexts.

Extinction challenge.-We implemented identical extinction challenges in both contexts. During this phase, we placed FCRs and destructive behavior on extinction. The extinction 
challenge ended after two consecutive sessions with at least an $85 \%$ decrease in baseline rates of destructive behavior in both contexts.

\section{Results and Discussion}

Table 1 displays target (destructive behavior) and alternative (FCR) response rates (expressed as responses per min) and reinforcement rates (expressed as reinforcers per min) for Marcus, Ace, Bernie, and Owen across baseline, FCT, and extinction-challenge phases of Study 1 . We did not observe any instances of destructive behavior during reinforcement intervals with Bernie and Owen; and we observed near zero rates of destructive behavior during reinforcement intervals with Ace and Marcus. Reinforcer rates were calculated both based on the overall session duration as well as the session duration minus reinforcer consumption time (i.e., time from the 20 -s periods during which participants accessed functional reinforcers). We calculated reinforcer rates using both methods because, from a clinical perspective, destructive behavior may occur at any point during a session, and it is important to include responding during all times to accurately judge the overall efficacy of an intervention. In contrast, previous research on resurgence has calculated reinforcer rate by excluding the 20-s reinforcement periods from the denominator (e.g., Craig, Browning, Nall, Marshall, \& Shahan, 2017; Nevin et al., 2016; Thrailkill, Kimball, Kelley, Craig, \& Podlesnik, 2018). The $S^{R_{S}}$ columns in Table 1 display the results of both calculations with reinforcers per min expressed for dense and lean schedules both when the 20-s reinforcement period was included and excluded. Our reinforcer-rate differentials were much greater when reinforcer consumption time was excluded, consistent with previous investigations of reinforcer rates as a variable affecting the occurrence of resurgence.

Figure 1 shows destructive behavior per min for each participant across sessions. Marcus engaged in higher rates of destructive behavior under the leaner (VI $9 \mathrm{~s}$ ) of the two baseline schedules of reinforcement. Destructive behavior for Marcus was initially more persistent in the context associated with the denser (VI $2 \mathrm{~s}$ ) of the two schedules of reinforcement in baseline when therapists initiated FCT. Following a clear reduction in baseline rates of destructive behavior in both FCT conditions, therapists initiated the extinction challenge with Marcus, which showed higher rates of responding in the context associated with the denser schedule of reinforcement in baseline. Relative to the final six FCT sessions conducted across conditions, response rates during the extinction challenge were higher in three of the seven sessions of the dense baseline condition but were similarly high in only one of the seven sessions of the lean baseline condition.

Ace engaged in similar rates of destructive behavior across the two baseline schedules of reinforcement, with slightly higher rates under the lean (VI 14-s) schedule. Responding in both conditions was similarly persistent when therapists initiated FCT. Following a clear reduction in baseline rates of destructive behavior in both conditions during FCT, therapists initiated the extinction challenge with Ace. Rates of destructive behavior were similarly low across the two conditions.

Results for Bernie were similar to those obtained for Ace. Bernie engaged in similar rates of destructive behavior across the two baseline schedules of reinforcement, with only slightly higher rates under the lean (VI 90-s) schedule, despite the dense schedule producing more 
than 5 times the rate of reinforcement $(M s=2.3$ reinforcers per min in dense versus 0.5 reinforcers per min in lean; see Table 1). Functional communication training quickly suppressed high rates of destructive behavior observed in baseline, with little difference in efficacy between the two conditions. Low and undifferentiated response rates continued when therapists introduced the extinction challenge.

Owen engaged in substantially higher rates of destructive behavior under the lean (VI 14-s) schedule of reinforcement in baseline than under the dense (VI 2-s) schedule. However, FCT eliminated all instances of destructive behavior in both conditions. Therapists then terminated FCT with the introduction of the extinction challenge, and Owen's destructive behavior resurged in both conditions. Relative to the three FCT sessions conducted across conditions, response rates were higher during the extinction challenge in three of the five sessions of the dense baseline condition but were similarly high in only two of the five sessions of the lean baseline condition.

Expressing data as a proportion of baseline allows one to control for differences in response rates related to the schedule components and is the principal method to evaluate behavioral persistence and relapse in basic research on BMT (Craig et al., 2014; Mace et al., 2010; Nevin, 1988; Nevin, Tota, Torquato, \& Shull, 1990). Figure 2 displays proportion-ofbaseline responding during the FCT and extinction-challenge phases for Marcus, Ace, Bernie, and Owen in Study 1. All proportion-of-baseline calculations are expressed as the rate of destructive behavior in a given session, divided by the average rate of destructive behavior observed across all baseline sessions for that condition. Resurgence of destructive behavior occurred for only two of the four participants, but when it did occur, proportionsof-baseline responding were consistently higher in the condition associated with the denser of the two schedules of reinforcement used in baseline.

\section{Study 2: Applied Evaluation of Baseline Reinforcement Rate on Resurgence}

The results of Study 1 are generally consistent with previous research on resurgence demonstrating that higher rates of reinforcement during baseline are associated with greater levels of resurgence during extinction challenges (Fisher et al., in press; Kuroda, Cançado, \& Podlesnik, 2016; Podlesnik \& Shahan, 2009; Podlesnik \& Shahan, 2010). One factor that makes Study 1 unique is that we programmed VI schedules of reinforcement for destructive behavior in baseline and for FCRs during FCT. By and large, these reinforcement conditions are not analogous to the manner in which FCT is typically evaluated. For instance, applied behavior analysts typically program continuous schedules of reinforcement (i.e., FR 1) during FAs (i.e., baseline) and similarly dense schedules of reinforcement for FCRs during FCT (Hagopian, Jarmolowicz, \& Boelter, 2011; Tiger et al., 2008). For this reason, we designed Study 2 to further test the predictions of BMT as they relate to the resurgence of destructive behavior, by modeling conditions that more closely approximate common treatment procedures.

\section{Procedures}

Experimental procedures in Study 2 were implemented in a manner identical to those in Study 1, except as noted. Sessions lasted 5 min for Ryan and 10 min for Harvey and Tamra. 
Baseline.-We conducted two baseline conditions, one in each stimulus context.

Dense.: Baseline sessions during this condition were identical to the tangible condition of the FA for Ryan and the escape condition for Harvey and Tamra. Destructive behavior produced reinforcement according to an FR 1 schedule.

Lean.: Procedures in this context were identical to those in the dense baseline context except that destructive behavior produced the functional reinforcer according to a VI 30-s schedule. All reinforcers were arranged according to VI schedules by sampling without replacement from a predetermined list of 12 intervals (Fleshler \& Hoffman, 1962).

FCT.-We conducted identical FCT conditions across both contexts. During FCT, therapists placed destructive behavior on extinction and provided reinforcement for FCRs according to an FR 1 schedule.

Extinction Challenge.-We conducted identical extinction conditions across both contexts. During the extinction challenge, both FCRs and destructive behavior were placed on extinction.

\section{Results and Discussion}

Table 2 displays target (destructive behavior) and alternative (FCR) response rates (expressed as responses per min) and reinforcement rates (expressed as reinforcers per min) for Harvey, Ryan, and Tamra across baseline, FCT, and extinction-challenge phases of Study 2. Similar to Study 1 we calculated reinforcer rate using two methods: based on the total session duration, and based on the session duration minus all reinforcer consumption time. As with Study 1, reinforcer-rate differentials were much greater when reinforcer consumption time was excluded.

Figure 3 shows destructive behavior per min for each participant across sessions. Harvey engaged in higher rates of destructive behavior under the leaner (VI $30 \mathrm{~s}$ ) of the two baseline schedules of reinforcement; however, rates of destructive behavior were equally low and undifferentiated across the two conditions during FCT. The extinction challenge produced a slightly higher overall rate of destructive behavior in the lean baseline condition. Relative to the final six FCT sessions conducted across conditions, response rates during the extinction challenge were higher in three of the five sessions of the dense baseline condition and in three of the five sessions of the lean baseline condition.

Ryan engaged in highly variable rates of destructive behavior across the two conditions in baseline, but overall response rates were higher in the lean baseline condition. Destructive behavior was equally well suppressed across the two conditions during FCT. Destructive behavior resurged in only the dense baseline condition and in only one session. Relative to the final six FCT sessions conducted across conditions, response rates during the extinction challenge were higher in one of the four sessions of the dense baseline condition but did not occur in any of the four sessions of the lean baseline condition. 
Tamra engaged in more variable but higher overall rates of destructive behavior in the lean baseline condition. Similar to the results obtained for Harvey and Ryan, FCT suppressed baseline rates of destructive behavior similarly well across the two conditions. When therapists suspended FCT and initiated the extinction challenge, destructive behavior resurged in both conditions. Relative to the final six FCT sessions conducted across conditions, response rates during the extinction challenge were higher in four of the six sessions of the dense baseline condition but were similarly high in only three of the six sessions of the lean baseline condition.

Figure 4 displays proportion-of-baseline responding during the FCT and extinctionchallenge phases for Harvey, Ryan, and Tamra. Resurgence of destructive behavior occurred for all three participants in Study 2, though the fact that destructive behavior occurred at a non-zero rate during only one session of Ryan's extinction challenge limits the extent to which we can make meaningful conclusions about resurgence for this participant. Nevertheless, proportions-of-baseline responding were consistently higher in the condition associated with the denser of the two schedules of reinforcement used in baseline.

Across all participants in Studies 1 and 2, FCT led to marked and sustained decreases in baseline rates of destructive behavior, which provided a stable baseline from which we could evaluate resurgence when therapists discontinued FCT during the extinction challenge. To help better analyze the degree to which destructive behavior resurged in the dense baseline condition relative to the lean baseline condition, we adapted the relative resistance-to-change calculation described by Grace and Nevin (1997) to account for the relative levels of resurgence we observed across the two conditions in Studies 1 and 2. We calculated relative resurgence by taking the logarithm of the average proportion-of-baseline responding in the dense baseline condition divided by the average proportion-of-baseline responding in the lean baseline condition. Because FCT eliminated or greatly suppressed rates of destructive behavior prior to the extinction challenge for all participants, positive values in either study would indicate greater resurgence of destructive behavior in the dense baseline condition, negative values would indicate greater resurgence of destructive behavior in the lean baseline condition, and neutral values would indicate undifferentiated levels of resurgence. Figure 5 displays relative resurgence of destructive behavior for all participants in Studies 1 and 2. Across both studies, the majority of relative-resurgence measures was positive, and no participant showed substantially greater resurgence in the lean baseline condition.

\section{General Discussion}

We compared the effects of delivering relatively high-rate and low-rate reinforcement for destructive behavior in baseline on levels of resurgence following FCT across two studies. In both studies, we used a two-condition multielement design to arrange differential rates of baseline reinforcement for destructive behavior. In Study 1, we used reinforcement schedules similar to those typically used in basic and translational investigations of resurgence (see Shahan \& Craig, 2017 for a review). Destructive behavior produced either high-rate or low-rate reinforcement according to VI schedules during baseline, and FCRs produced reinforcement according to the identical VI schedules during FCT. We conducted Study 2 to assess resurgence following conditions that more closely approximate treatment 
as usual. Specifically, because continuous-reinforcement schedules are the most commonly used reinforcement strategy in FAs (Hanley, Iwata, \& McCord, 2003), high-rate reinforcement for destructive behavior was delivered according to an FR 1 schedule, similarly to the conditions of reinforcement for destructive behavior that clinicians often arrange during FA baseline conditions, while low-rate reinforcement was delivered according to a VI schedule. Further, FCRs produced reinforcers according to FR 1 schedules during FCT, similarly to conventional applications of FCT in clinical situations (Petscher, Rey, \& Bailey, 2009; Tiger et al., 2008).

Although we used different reinforcement schedules in Studies 1 and 2, we observed variable but similar relations between reinforcer rates for destructive behavior and resurgence following termination of FCT in both studies. Specifically, we observed that relatively high-rate reinforcement resulted in greater resurgence following FCT than relatively low-rate reinforcement. These findings are consistent with the prediction of BMT (see Craig et al., 2014; Nevin \& Shahan, 2011; Shahan \& Sweeney, 2011), which states that resurgence of operant behavior is governed by the Pavlovian association between discriminative stimuli and reinforcers that are delivered in their presence. As reinforcer rate increases, the Pavlovian stimulus-reinforcer relation in a specific discriminative-stimulus situation is strengthened, thereby making behavior more susceptible to resurge when alternative reinforcement is discontinued.

Basic-research studies on previously reinforced and then extinguished behavior inspired our current investigation. For example, Podlesnik and Shahan (2009; see also Podlesnik \& Shahan, 2010) trained pigeons to peck keys in a two-component multiple schedule. In baseline, they programmed reinforcement for target-key pecking using equal VI 120-s schedules in both components, but they provided additional food on a time-based schedule in the high-rate component (i.e., according to a variable-time [VT] 20-s schedule). Next, in both components they extinguished target-key pecking and programmed reinforcement according to VI 30-s schedules for pecking an illuminated, alternative key. Finally, they suspended reinforcement for pecking the alternative key to test for resurgence. Target-key pecking persisted to a greater degree during extinction plus alternative reinforcement and resurged to a greater degree when they suspended alternative reinforcement in the component associated with the higher rate $(\mathrm{VI}+\mathrm{VT}$ ) of baseline reinforcement (see also Kuroda et al., 2016).

The present studies translated procedures like those used by Podlesnik and Shahan (2009) and, importantly, replicated their principal finding that target behavior is more likely to resurge following relatively higher rates of baseline reinforcement with human participants in a clinical setting and while treating severe destructive behavior. Our studies, however, did not replicate Podlesnik and Shahan's finding that higher rates of baseline reinforcement produced greater persistence of target behavior during the second phase of our study when we programmed extinction for destructive behavior and equal rates of alternative reinforcement for the FCR. Two procedural details from our studies could have been responsible for this discrepancy. First, we included FCT-pretraining phases in both of our studies. It is reasonable to believe that the progressive-prompt delays used in pretraining facilitated participants' rapid reallocation of responding from target destructive behavior to 
FCRs during FCT (indeed, target behavior occurred at near-zero rates for all participants in most sessions of FCT; see Figures 1 and 3). Also, the presentation of the FCR card likely functioned as a discriminative stimulus for the availability of reinforcement contingent on card exchanges and might have aided in the immediate suppression of destructive behavior during FCT for Bernie and Owen. Thus, a floor effect might preclude full analysis of differential resistance to extinction between multielement-schedule conditions. Second, we used very high rates of reinforcement in the high-rate condition of both studies (i.e., VI $2 \mathrm{~s}$ in Study 1 and FR 1 in Study 2). At extremely high reinforcer rates, the well-established positive relation between reinforcer rates and persistence of discriminated operant behavior is reduced or may even be reversed (the well-known partial-reinforcement extinction effect; Nevin \& Grace, 2005). The exact reasons that resistance to extinction of discriminated operant behavior is sometimes positively and sometimes negatively related to pre-extinction reinforcer rates remain uncertain (for discussion, see Craig \& Shahan, 2016b; Craig \& Shahan, 2018; Nevin, 2012; Nevin et al., 2017). At any rate, the present data might not be particularly well suited for evaluation of this somewhat equivocal relation.

Despite our consistent finding that when we observed resurgence of destructive behavior, it occurred to a greater degree following high-rate than following low-rate baseline reinforcement, it is important to note that we observed resurgence reliably for just four of seven participants across Studies 1 and 2. No noticeable increase in destructive behavior occurred for Ace or Bernie in Study 1, and destructive behavior only occurred at a non-zero rate during one session of the extinction challenge for Ryan in Study 2. However, it is important to note that resurgence is not ubiquitous following suspension of reinforcement for alternative behavior, even in the animal laboratory under highly controlled conditions. For example, in the most extensive parametric analysis of reinforcer-rate effects on resurgence to date, Craig and Shahan (2016a) studied resurgence of rats' lever pressing following high- and low-rate reinforcement for target and alternative behavior. Of the 24 rats that experienced alternative reinforcement, 10 did not show a substantial increase ( $>1$ response per min) in lever pressing during an extinction challenge (see Appendix B of that study). Thus, with relatively small-n studies, like those reported here, it should not be surprising that resurgence occurred for only a subset of participants. Future basic and applied research should focus on identifying subject and participant variables that help to determine whether resurgence of previously reinforced behavior is likely to occur.

Notwithstanding these potential interpretive limitations, the findings from the present series of studies, in combination with those from previous analyses (e.g., Dube, Mcllvane, Mazzitelli, \& McNamara, 2003; Fisher et al., in press; Mace et al., 2010; Nevin et al., 2016; Pritchard, Hoerger, Mace, Penney et al., 2014), have potentially important implications for understanding variables that contribute toward resurgence in applied settings. That is, delivering high rates of reinforcement (e.g., FR 1 or similarly dense schedules) for destructive behavior during baseline appears to increase the risk of subsequent resurgence of destructive behavior during periods in which programmed reinforcement for the alternative response during FCT cannot be delivered. The current findings, along with those of related basic and translational research, suggest programming a lower rate of reinforcement for destructive behavior during baseline might help protect against forms of treatment relapse involving resurgence of destructive behavior. 
As indicated across Studies 1 and 2, arranging leaner schedules of reinforcement in baseline is likely to produce higher rates of destructive behavior, which may severely limit the applied utility of this strategy for mitigating resurgence. Although leaner schedules of reinforcement in baseline was associated with less resurgence compared to the densereinforcement-schedule baseline, it was associated with higher (e.g., Harvey, Tamra) and more variable (e.g., Ryan) levels of destructive behavior during the initial phase. One important limitation of using leaner schedules of reinforcement during baseline is that reductions in the rate of reinforcement (such as those that occur in lean VI schedules) could produce negative side effects similar to extinction (e.g., variable and higher rates of destructive behavior, extinction-induced variability, emotional responding; Vollmer et al., 1998, see also Dube, Mazzitelli, Lombard, \& McIlvane, 2000 for a related discussion). Therefore, the potential risk associated with arranging lean schedules of reinforcement during baseline precludes conclusive recommendations for clinical practice.

Although the resurgence of destructive behavior when FCT is abruptly discontinued is a serious concern in applied settings, it is also important to note that the emerging technology of reinforcement-schedule thinning has been an effective method for decreasing the overall rate of reinforcement for communicative behavior while maintaining low levels of destructive behavior during FCT (Greer et al., 2016). For example, the use of multiple schedules of reinforcement, chained schedules of reinforcement, and delay fading have all shown to have reasonable success in exposing communication responses to progressively longer periods of extinction (Hagopian et al., 2011; Saini, Miller, \& Fisher, 2016, however see Briggs et al., 2018). Future researchers should consider methods to increase the practicality of reinforcement-schedule thinning procedures as advancements in this area may be a logical extension of traditional FCT interventions.

Our findings underscore the potential importance of insights from the experimental analysis of behavior generally, and the quantitative analysis of behavior in particular, for applied practice (for additional discussion, see Dube, Ahearn, Lionello-DeNolf, \& Mcllvane, 2009; Mace, 2018; Podlesnik \& DeLeon, 2015). Quantitative analyses provide applied researchers with more precise models for describing functional relations between treatment manipulations and target responses. They also allow clinicians to make precise predictions regarding the effects a treatment is likely to have on a target response with greater precision. Moreover, as in the current case, the specific predictions of quantitative models of behavior could help to identify unforeseen consequences of treatment that contraindicate common clinical practices, such as delivering reinforcement during baseline on a partial reinforcement schedule. Quantitative models also have the potential to help applied researchers and clinicians develop more efficient and effective strategies for promoting enduring behavior change. We encourage readers to view quantitative models of behavior processes as potential tools for informing the development of more effective treatment protocols.

\section{Acknowledgments}

Grants \#5R01HD079113, \#5R01HD083214, and \#1R01HD093734 from The National Institute of Child Health and Human Development provided partial support for this work. 


\section{References}

Beavers GA, Iwata BA, \& Lerman DC (2013). Thirty years of research on the functional analysis of problem behavior. Journal of Applied Behavior Analysis, 46, 1-21. doi:10.1002/jaba.30 [PubMed: 24114081]

Betz AM, Fisher WW, Saini V (in press). Functional analysis: History and methods In Fisher WW, Piazza CC, \& Roane HS (Eds.), Handbook of Applied Behavior Analysis, 2nd Edition New York, NY: Guilford.

Briggs AM, Fisher WW, Greer BD, \& Kimball RT (2018). Prevalence of resurgence of destructive behavior when thinning reinforcement schedules during functional communication training. Journal of Applied Behavior Analysis, 51, 620-633. doi:10.1002/jaba.472 [PubMed: 29774545]

Cançado CRX, Abreu-Rodrigues J, \& Aló RM (2015). Reinforcement rate and resurgence: A parametric analysis. Mexican Journal of Behavior Analysis, 41, 84-115.

Charlop MH, Schreibman L, \& Thibodeau MG (1985). Increasing spontaneous verbal responding in autistic children using a time delay procedure. Journal of Applied Behavior Analysis, 18, 155-166. doi:10.1901/jaba.1985.18-155 [PubMed: 4019351]

Conners J, Iwata BA, Kahng S, Hanley GP, Worsdell AS, \& Thompson RH (2000). Differential responding in the presence and absence of discriminative stimuli during multielement functional analyses. Journal of Applied Behavior Analysis, 33, 299-308. doi:10.1901/jaba.2000.33-299 [PubMed: 11051570]

Craig AR, Browning KO, Nall RW, Marshall CM, \& Shahan TA (2017). Resurgence and alternativereinforcer magnitude. Journal of the Experimental Analysis of Behavior, 107, 218-233. doi: 10.1002/jeab.245 [PubMed: 28194793]

Craig AR, Nevin JA, \& Odum AL (2014). Behavioral momentum and resistance to change In McSweeney FK \& Murphey ES (Eds.), The Wiley-Blackwell handbook of operant and classical conditioning (pp. 249-274). Oxford, UK: Wiley-Blackwell.

Craig AR, \& Shahan TA (2016a). Behavioral momentum theory fails to account for the effects of reinforcement rate on resurgence. Journal of the Experimental analysis of Behavior, 105, 375-392. doi:10.1002/jeab.207 [PubMed: 27193242]

Craig AR, \& Shahan TA (2016b). Experience with dynamic reinforcement rates decreases resistance to extinction. Journal of the Experimental Analysis of Behavior, 105, 291-306. doi: 10.1002/jeab.196 [PubMed: 26813330]

Craig AR, \& Shahan TA (2018). Multiple schedules, off-baseline reinforcement shifts, and resistance to extinction. Journal of the Experimental Analysis of Behavior, 109, 148-163. doi: 10.1002/jeab. 300 [PubMed: 29293265]

Didden R, Duker PC, \& Korzilius H (1997). Meta-analytic study on treatment effectiveness for problem behaviors with individuals who have mental retardation. American Journal on Mental Retardation, 101, 387-399. [PubMed: 9017085]

Didden R, Korzilius H, van Oorsouw W, \& Sturmey P (2006). Behavioral treatment of challenging behaviors in individuals with mild mental retardation: Meta-analysis of single-subject research American Journal on Mental Retardation, 111, 290-298. [PubMed: 16792430]

Doughty AH, \& Oken G (2008). Extinction-induced response resurgence: A selective review. The Behavior Analyst Today, 9, 27-33.

Dube WV, Ahearn WH, Lionello-DeNolf K, \& McIlvane WJ (2009). Behavioral momentum: Translational research in intellectual and developmental disabilities. The Behavior Analyst Today, 10, 238-253. [PubMed: 20936093]

Dube WV, Mazzitelli K, Lombard KM, \& McIlvane WJ (2000). Assessing behavioral momentum in humans with mental retardation and unstable baselines. Experimental Analysis of Human Behavior Bulletin, 18, 6-11.

Dube WV, McIlvane WJ, Mazzitelli K, \& McNamara B (2003). Reinforcer rate effects and behavioral momentum in individuals with developmental disabilities. American Journal on Mental Retardation, 108, 134-143. [PubMed: 12564945]

Findley JD (1958). Preference and switching under concurrent scheduling. Journal of the Experimental Analysis of Behavior, 1, 123-144. doi:10.1901/jeab.1958.1-123 [PubMed: 16811208] 
Fisher WW, Greer BD, Craig AR, Retzlaff BJ, Fuhrman AM, Lichtblau KR, \& Saini V (2018). On the predictive validity of behavioral momentum theory for mitigating resurgence of problem behavior. Journal of the Experimental Analysis of Behavior, 109, 281-290. doi:10.1002/jeab.303 [PubMed: 29380437]

Fisher WW, Greer BD, Fuhrman AM, Saini V, \& Simmons CA (in press). Minimizing resurgence of destructive behavior using behavioral momentum theory. Journal of Applied Behavior Analysis.

Fisher W, Piazza CC, Bowman LG, Hagopian LP, Owens JC, \& Slevin I (1992). A comparison of two approaches for identifying reinforcers for persons with severe and profound disabilities. Journal of Applied Behavior Analysis, 25, 491-498. doi:10.1901/jaba.1992.25-491 [PubMed: 1634435]

Fisher WW, Piazza CC, Cataldo MF, Harrell R, Jefferson G, \& Conner R (1993). Functional communication training with and without extinction and punishment. Journal of Applied Behavior Analysis, 26, 23-36. doi:10.1901/jaba.1993.26-23 [PubMed: 8473256]

Fleshler M, \& Hoffman HS (1962). A progression for generating variable-interval schedules. Journal of the Experimental Analysis of Behavior, 5, 529-530. doi:10.1901/jeab.1962.5-529 [PubMed: 13945507]

Fuhrman AM, Fisher WW, \& Greer BD (2016). A preliminary investigation on improving functional communication training by mitigating resurgence of destructive behavior. Journal of Applied Behavior Analysis, 49, 884-899. doi:10.1002/jaba.338 [PubMed: 27449566]

Fujimaki S, Lattal KA, \& Sakagami T (2015). Further look at reinforcement rate and resurgence. Mexican Journal of Behavior Analysis, 41, 116-136.

Grace RC, \& Nevin JA (1997). On the relation between preference and resistance to change. Journal of the Experimental Analysis of Behavior, 67, 43-65. doi:10.1901/jeab.1997.67-43 [PubMed: 16812830]

Greer BD, Fisher WW, Romani PW, \& Saini V (2016). Behavioral momentum theory: A tutorial on response persistence. The Behavior Analyst, 39, 269-291. doi:10.1007/s40614-016-0050-0

Greer BD, Fisher WW, Saini V, Owen TM, \& Jones JK (2016). Functional communication training during reinforcement schedule thinning: An analysis of 25 applications. Journal of Applied Behavior Analysis, 49, 105-121. doi:10.1002/jaba.265 [PubMed: 26482103]

Hagopian LP, Boelter EW, \& Jarmolowicz DP (2011). Reinforcement schedule thinning following functional communication training: Review and recommendations. Behavior Analysis in Practice, 4, 4-16.

Hanley GP (2012). Functional assessment of problem behavior: Dispelling myths, overcoming implementation obstacles, and developing new lore. Behavior Analysis in Practice, 5, 54-72. [PubMed: 23326630]

Hanley GP, Iwata BA, \& McCord BE (2003). Functional analysis of problem behavior: A review. Journal of Applied Behavior Analysis, 36, 147-185. doi:10.1901/jaba.2003.36-147 [PubMed: 12858983]

Hanley GP, Iwata BA, \& Thompson RH (2001). Reinforcement schedule thinning following treatment with functional communication training. Journal of Applied Behavior Analysis, 34, 17-38. doi: 10.1901/jaba.2001.34-17 [PubMed: 11317985]

Hanley GP, Piazza CC, Fisher WW, Contrucci SA, \& Maglieri KA (1997). Evaluation of client preference for function-based treatment packages. Journal of Applied Behavior Analysis, 30, 459473. doi:10.1901/jaba.1997.30-459 [PubMed: 9316259]

Herrnstein RJ (1961). Relative and absolute strength of response as a function of frequency of reinforcement. Journal of the Experimental Analysis of Behavior, 4, 267-272. doi: 10.1901/jeab. 1961.4-267 [PubMed: 13713775]

Iwata BA, Dorsey MF, Slifer KJ, Bauman KE, \& Richman GS (1994). Toward a functional analysis of self-injury. Journal of Applied Behavior Analysis, 27, 197-209. (Reprinted from Analysis and Intervention in Developmental Disabilities, 2, 3-20, 1982). doi:10.1901/jaba.1994.27-197 [PubMed: 8063622]

Iwata BA, Duncan BA, Zarcone JR, Lerman DC, \& Shore BA (1994). A sequential, test-control methodology for conducting functional analyses of self-injurious behavior. Behavior Modification, 18, 289-306. [PubMed: 8037650] 
Iwata BA, Pace GM, Dorsey MF, Zarcone JR, Vollmer TR, Smith RG, .. \& \& Goh HL (1994). The functions of self-injurious behavior: An experimental-epidemiological analysis. Journal of Applied Behavior Analysis, 27, 215-240. doi:10.1901/jaba.1994.27-215 [PubMed: 8063623]

Kodak T, Campbell V, Bergmann S, LeBlanc B, Kurtz-Nelson E, Cariveau T, \& ... Mahon J (2016). Examination of efficacious, efficient, and socially valid error-correction procedures to teach sight words and prepositions to children with autism spectrum disorder. Journal of Applied Behavior Analysis, 49, 532-547. doi:10.1002/jaba.310 [PubMed: 27150389]

Kuroda T, Cançado CR, \& Podlesnik CA (2016). Resistance to change and resurgence in humans engaging in a computer task. Behavioural Processes, 125, 1-5. [PubMed: 26836390]

Lattal KA, \& St Peter Pipkin C (2009). Resurgence of previously reinforced responding: Research and application. The Behavior Analyst Today, 10, 254-266.

Leitenberg H, Rawson RA, \& Mulick JA (1975). Extinction and reinforcement of alternative behavior. Journal of Comparative and Physiological Psychology, 88, 640-652. doi:10.1037/h0076418

Lieving GA, Hagopian LP, Long ES, \& O'Connor J (2004). Response-class hierarchies and resurgence of severe problem behavior. The Psychological Record, 54, 621-634.

Lieving GA, \& Lattal KA (2003). Recency, repeatability, and reinforcer retrenchment: An experimental analysis of resurgence. Journal of the Experimental Analysis of Behavior, 80, 217 233. doi:10.1901/jeab.2003.80-217 [PubMed: 14674730]

Mace FC (2018). Tony Nevin: The embrace of translational work by a basic scientist. Journal of the Experimental Analysis of Behavior, 109, 56-65. doi: 10.1002/jeab.297 [PubMed: 29318629]

Mace FC, Lalli JS, Shea MC, Lalli EP, West BJ, Roberts M, \& Nevin JA (1990). The momentum of human behavior in a natural setting. Journal of the Experimental Analysis of Behavior, 54, 163172. doi:10.1901/jeab.1990.54-163 [PubMed: 16812621]

Mace FC, McComas JJ, Mauro BC, Progar PR, Taylor B, Ervin R, \& Zangrillo AN (2010). Differential reinforcement of alternative behavior increases resistance to extinction: Clinical demonstration, animal modeling, and clinical test of one solution. Journal of the Experimental Analysis of Behavior, 93, 349-367. doi:10.1901/jeab.2010.93-349 [PubMed: 21119850]

Mace FC, \& Nevin JA (2017). Maintenance, generalization, and treatment relapse: A behavioral momentum analysis. Education and Treatment of Children, 40, 27-42.

Nevin JA (1988). Behavioral momentum and the partial reinforcement effect. Psychological Bulletin, 103, 44-56. doi:10.1037/0033-2909.103.1.44

Nevin JA (2012). Resistance to extinction and behavioral momentum. Behavioural Processes, 90, 8997. [PubMed: 22425781]

Nevin JA, \& Baum WM (1980). Feedback functions for variable-interval reinforcement. Journal of the Experimental Analysis of Behavior, 34, 207-217. doi:10.1901/jeab.1980.34-207 [PubMed: 16812187]

Nevin JA, Craig AR, Cunningham PJ, Podlesnik CA, Shahan TA, \& Sweeney MM (2017). Quantitative models of persistence and relapse from the perspective of behavioral momentum theory: Fits and misfits. Behavioural Processes, 141, 92-99. doi: 10.1016/j.beproc.2017.04.016 [PubMed: 28465027]

Nevin JA, \& Grace RC (2005). Resistance to extinction in the steady state and in transition. Journal of Experimental Psychology: Animal Behavior Processes, 31, 199- Extinction-induced response resurgence: A selective review 212. [PubMed: 15839776]

Nevin JA, Mace FC, DeLeon IG, Shahan TA, Shamlian KD, Lit K, .. \& T Tarver DR (2016). Effects of signaled and unsignaled alternative reinforcement on persistence and relapse in children and pigeons. Journal of the Experimental Analysis of Behavior, 106, 34-57. doi:10.1002/jeab.213 [PubMed: 27282331]

Nevin JA, \& Shahan TA (2011). Behavioral momentum theory: Equations and applications. Journal of Applied Behavior Analysis, 44, 877-895. doi:10.1901/jaba.2011.44-877 [PubMed: 22219536]

Nevin JA, Tota ME, Torquato RD, \& Shull RL (1990). Alternative reinforcement increases resistance to change: Pavlovian or operant contingencies? Journal of the Experimental Analysis of Behavior, 53, 359-379. doi:10.1901/jeab.1990.53-359 [PubMed: 2341820] 
Petscher ES, Rey C, \& Bailey JS (2009). A review of empirical support for differential reinforcement of alternative behavior. Research in Developmental Disabilities, 30, 409-425. [PubMed: 18929460]

Podlesnik C, \& DeLeon I (2015). Behavioral momentum theory: Understanding persistence and improving treatment In DiGennaro RF, Reed D (Eds.), Autism Service Delivery. New York, NY: Springer.

Podlesnik CA, \& Kelley ME (2014). Resurgence: Response competition, stimulus control, and reinforcer control. Journal of the Experimental Analysis of Behavior, 102, 231-240. doi:10.1002/ jeab.102 [PubMed: 25125267]

Podlesnik CA \& Kelley ME (2015). Translational research on the relapse of operant behavior. Mexican Journal of Behavior Analysis, 41, 226-251.

Podlesnik CA, \& Shahan TA (2009). Behavioral momentum and relapse of extinguished operant responding. Learning \& Behavior, 37, 357-364. doi:10.3758/LB.37.4.357 [PubMed: 19815932]

Podlesnik CA, \& Shahan TA (2010). Extinction, relapse, and behavioral momentum. Behavioural Processes, 84, 400-411. [PubMed: 20152889]

Pritchard D, Hoerger M, \& Mace FC (2014). Treatment relapse and behavioral momentum theory. Journal of Applied Behavior Analysis, 47, 814-833. doi:10.1002/jaba.163 [PubMed: 25291317]

Pritchard D, Hoerger M, Mace FC, Penney H, \& Harris B (2014). Clinical translation of animal models of treatment relapse. Journal of the Experimental Analysis of Behavior, 101, 442-449. doi: 10.1002/jeab.87 [PubMed: 24700533]

Pritchard D, Hoerger M, Mace FC, Penney H, Harris B, \& Eiri L (2016). Clinical translation of the ABA renewal model of treatment relapse. European Journal of Behavior Analysis, 17, 182-191. doi:10.1080/15021149.2016.1251144

Querim AC, Iwata BA, Roscoe EM, Schlichenmeyer KJ, Ortega JV, \& Hurl KE (2013). Functional analysis screening for problem behavior maintained by automatic reinforcement. Journal of Applied Behavior Analysis, 46, 47-60. doi:10.1002/jaba.26 [PubMed: 24114084]

Rooker GW, Jessel J, Kurtz PF, \& Hagopian LP (2013). Functional communication training with and without alternative reinforcement and punishment: An analysis of 58 applications. Journal of Applied Behavior Analysis, 46, 708-722. doi:10.1002/jaba.76 [PubMed: 24114463]

Saini V, Miller SA, \& Fisher WW (2016). Multiple schedules in practical application: Research trends and implications for future investigation. Journal of Applied Behavior Analysis, 49, 421-444. doi: 10.1002/jaba.300 [PubMed: 26990754]

Shahan TA, \& Craig AR (2017). Resurgence as choice. Behavioural processes, 141, 100-127. doi: 10.1016/j.beproc.2016.10.006 [PubMed: 27794452]

Shahan TA, Magee A, \& Dobberstein A (2003). The resistance to change of observing. Journal of the Experimental Analysis of Behavior, 80, 273-293. doi: 10.1901/jeab.2003.80-273 [PubMed: 14964708]

Shahan TA, \& Sweeney MM (2011). A model of resurgence based on behavioral momentum theory. Journal of the Experimental Analysis of Behavior, 95, 91-108. doi:10.1901/jeab.2011.95-91 [PubMed: 21541118]

Sweeney MM, \& Shahan TA (2013). Effects of high, low, and thinning rates of alternative reinforcement on response elimination and resurgence. Journal of the Experimental Analysis of Behavior, 100, 102-116. doi:10.1002/jeab.26 [PubMed: 23605776]

Thrailkill EA, Kimball RT, Kelley ME, Craig AR, \& Podlesnik CA (2018). Greater reinforcement rate during training increases spontaneous recovery. Journal of the Experimental Analysis of Behavior, 109, 238-252. doi: 10.1002/jeab.307 [PubMed: 29314021]

Tiger JH, Hanley GP, \& Bruzek J (2008). Functional communication training: A review and practical guide. Behavior Analysis in Practice, 1, 16-23. [PubMed: 22477675]

Volkert VM, Lerman DC, Call NA, \& Trosclair-Lasserre N (2009). An evaluation of resurgence during treatment with functional communication training. Journal of Applied Behavior Analysis, 42, 145160. doi:10.1002/jaba.76 [PubMed: 19721735]

Vollmer TR, Progar PR, Lalli JS, Camp CM, Sierp BJ, Wright CS, .. \& Eisenschink KJ (1998). Fixed-time schedules attenuate extinction-induced phenomena in the treatment of severe aberrant 
behavior. Journal of Applied Behavior Analysis, 31, 529-542. doi:10.1901/jaba.1998.31-529 [PubMed: 9891392]

Wacker DP, Harding JW, Berg WK, Lee JF, Schieltz KM, Padilla YC, .. \& \& Shahan TA (2011). An evaluation of persistence of treatment effects during long-term treatment of destructive behavior. Journal of the Experimental Analysis of Behavior, 96, 261-282. doi:10.1901/jeab.2011.96-261 [PubMed: 21909168]

Wacker DP, Harding JW, Morgan TA, Berg WK, Schieltz KM, Lee JF, \& Padilla YC (2013). An evaluation of resurgence during functional communication training. The Psychological Record, 63, $3-20$.

Winterbauer NE, \& Bouton ME (2010). Mechanisms of resurgence of an extinguished instrumental behavior. Journal of Experimental Psychology: Animal Behavior Processes, 36, 343-353. doi: 10.1037/a0017365 [PubMed: 20658865]

Winterbauer NE, \& Bouton ME (2012). Effects of thinning the rate at which the alternative behavior is reinforced on resurgence of an extinguished instrumental response. Journal of Experimental Psychology: Animal Behavior Processes, 38, 279-291. doi:10.1037/a0028853 [PubMed: 22823421] 


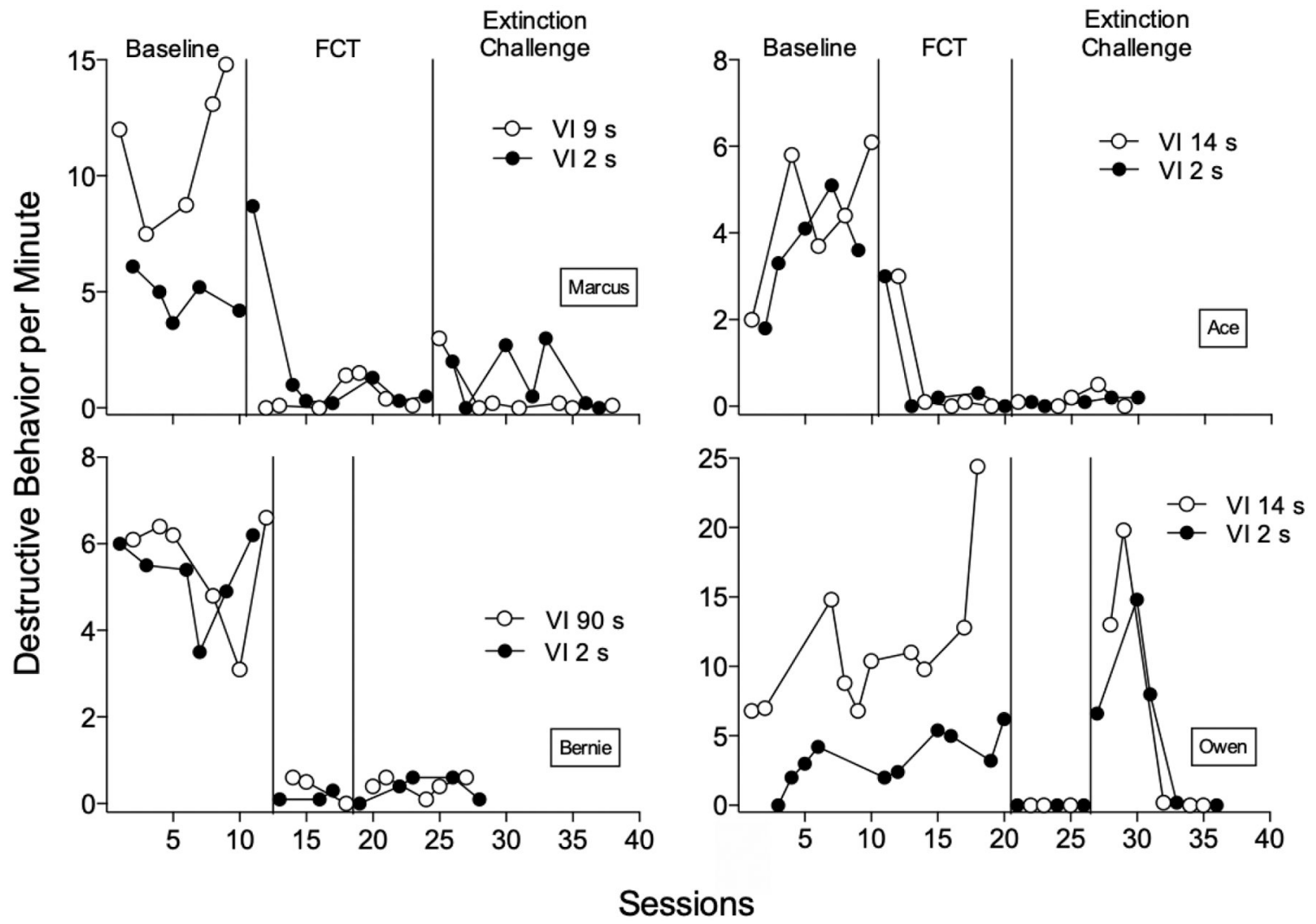

Figure 1.

Destructive behavior per min for Marcus, Ace, Bernie, and Owen in each phase of Study 1. 


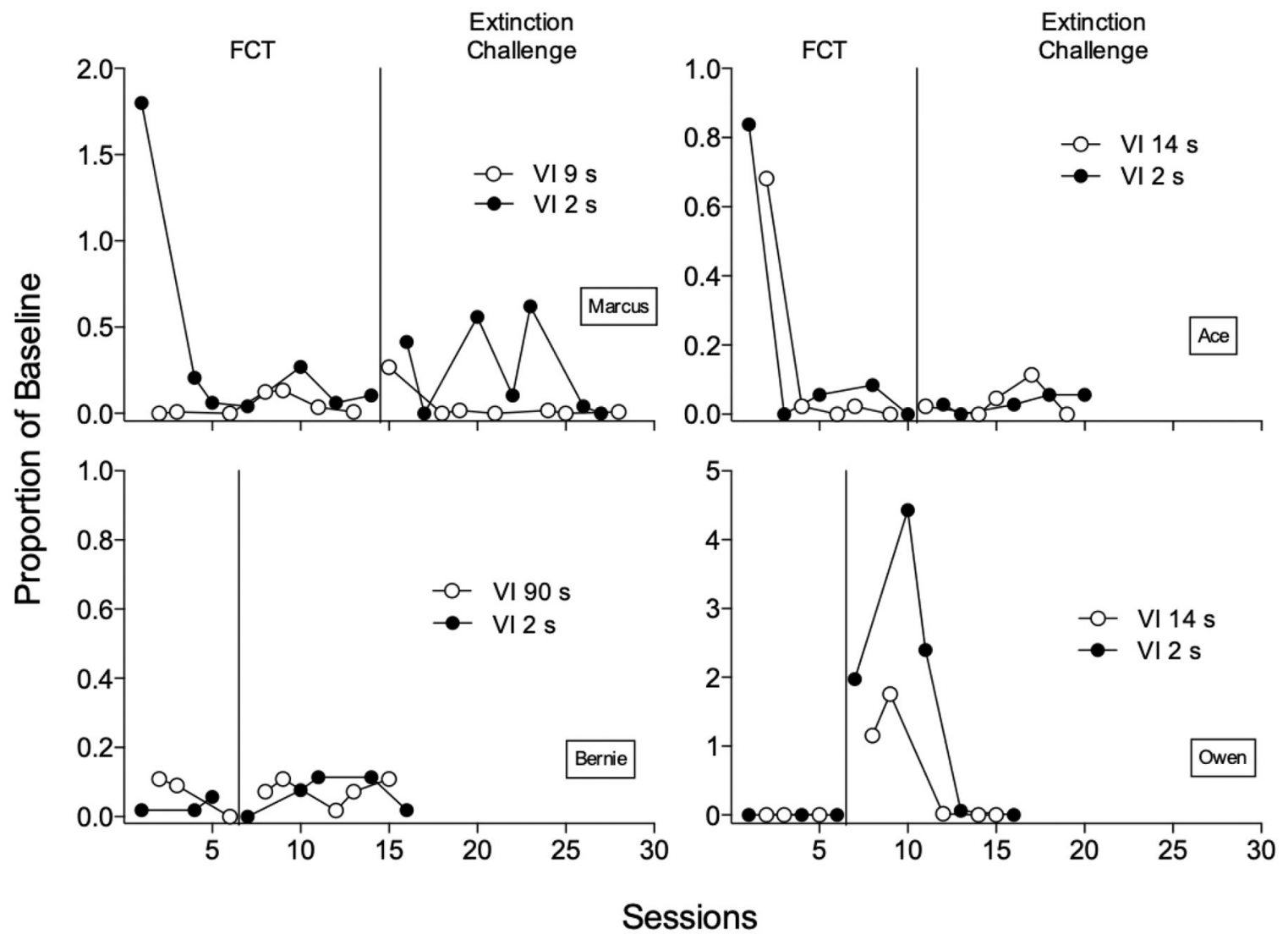

Figure 2.

Proportion-of-baseline destructive behavior during the FCT and extinction-challenge phases for Marcus, Ace, Bernie, and Owen in Study 1. 


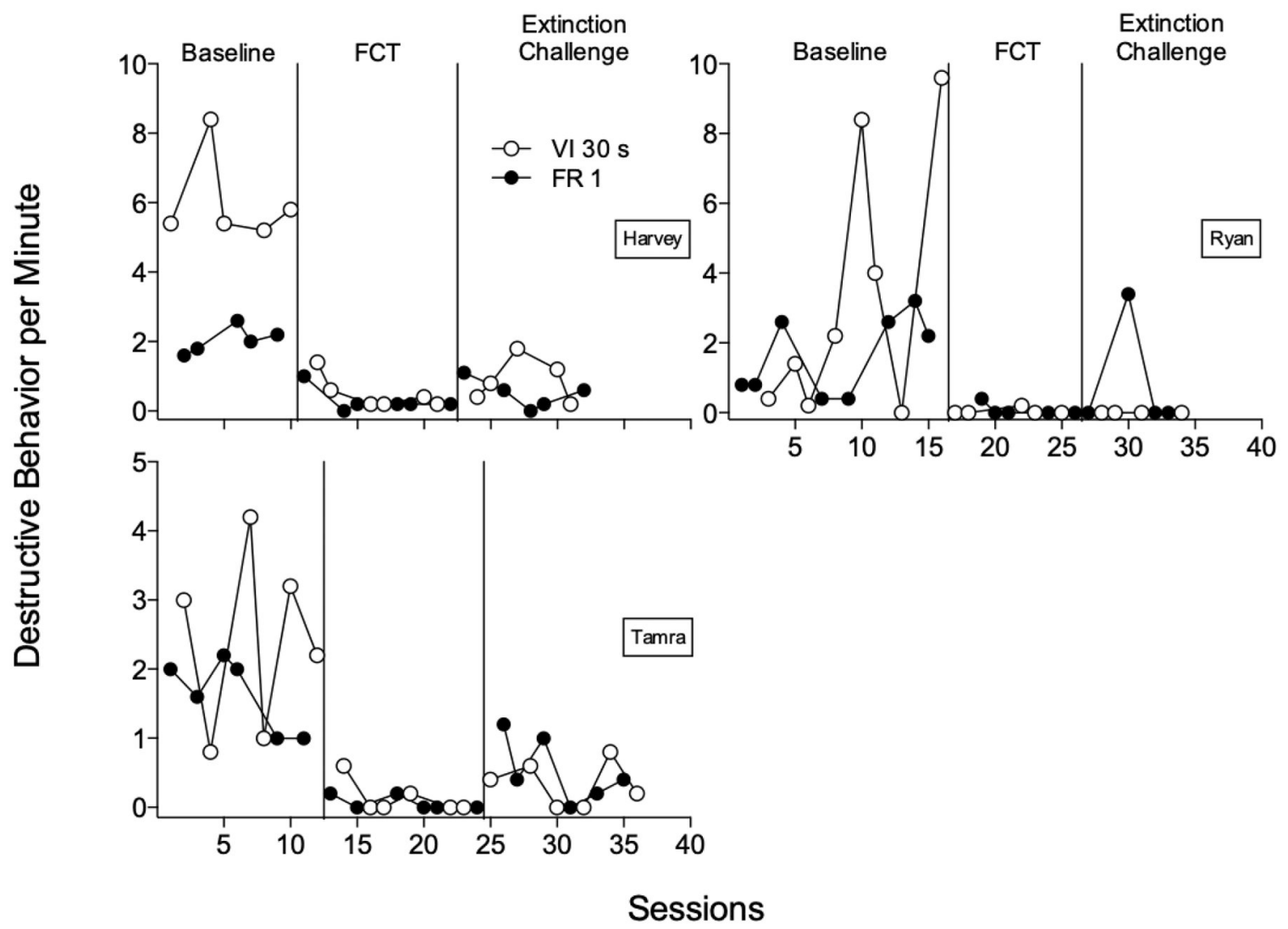

Figure 3.

Destructive behavior per min for Harvey, Ryan, and Tamra in each phase of Study 2. 

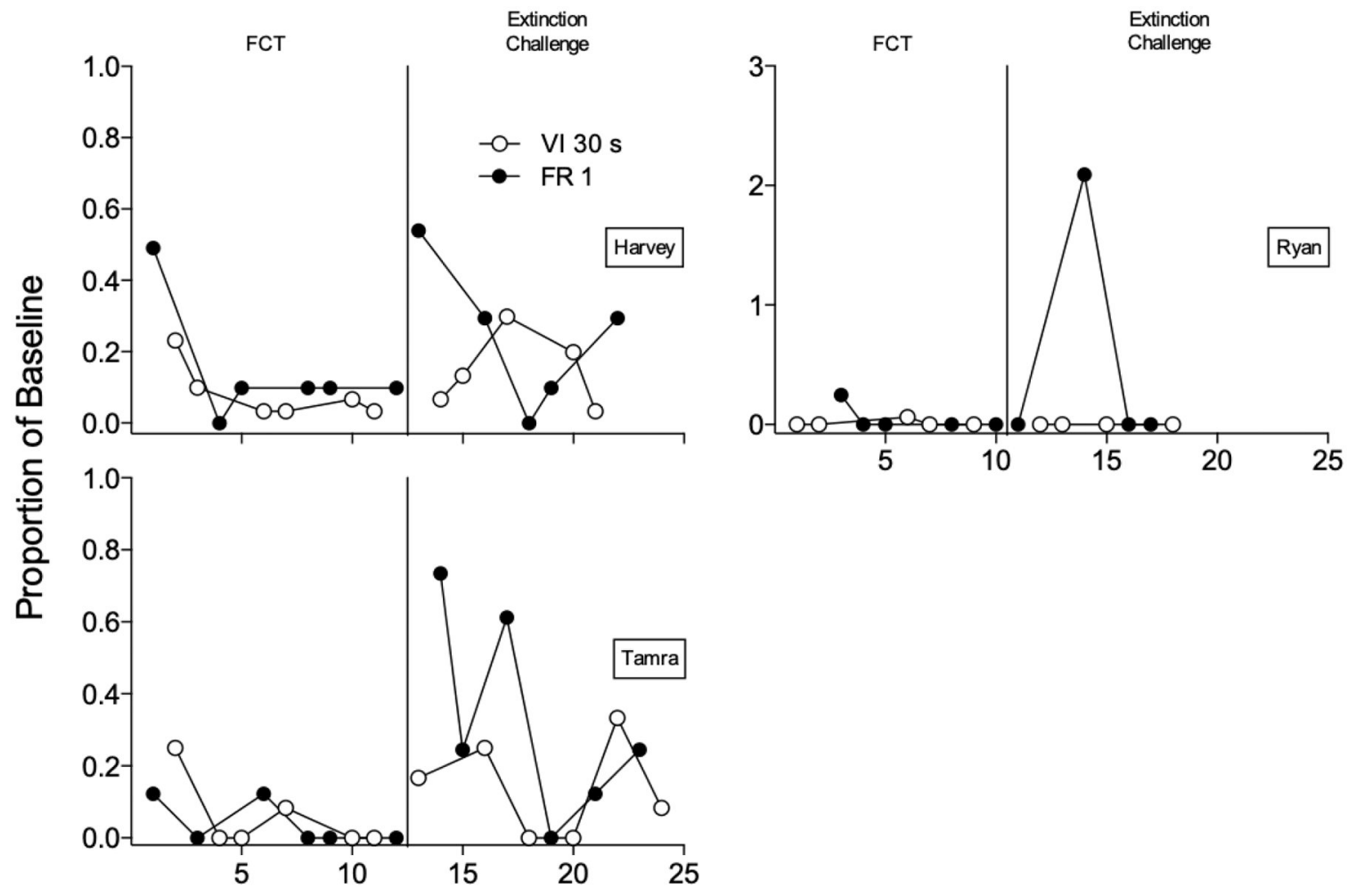

Sessions

Figure 4.

Proportion-of-baseline destructive behavior during the FCT and extinction-challenge phases for Harvey, Ryan, and Tamra in Study 2. 


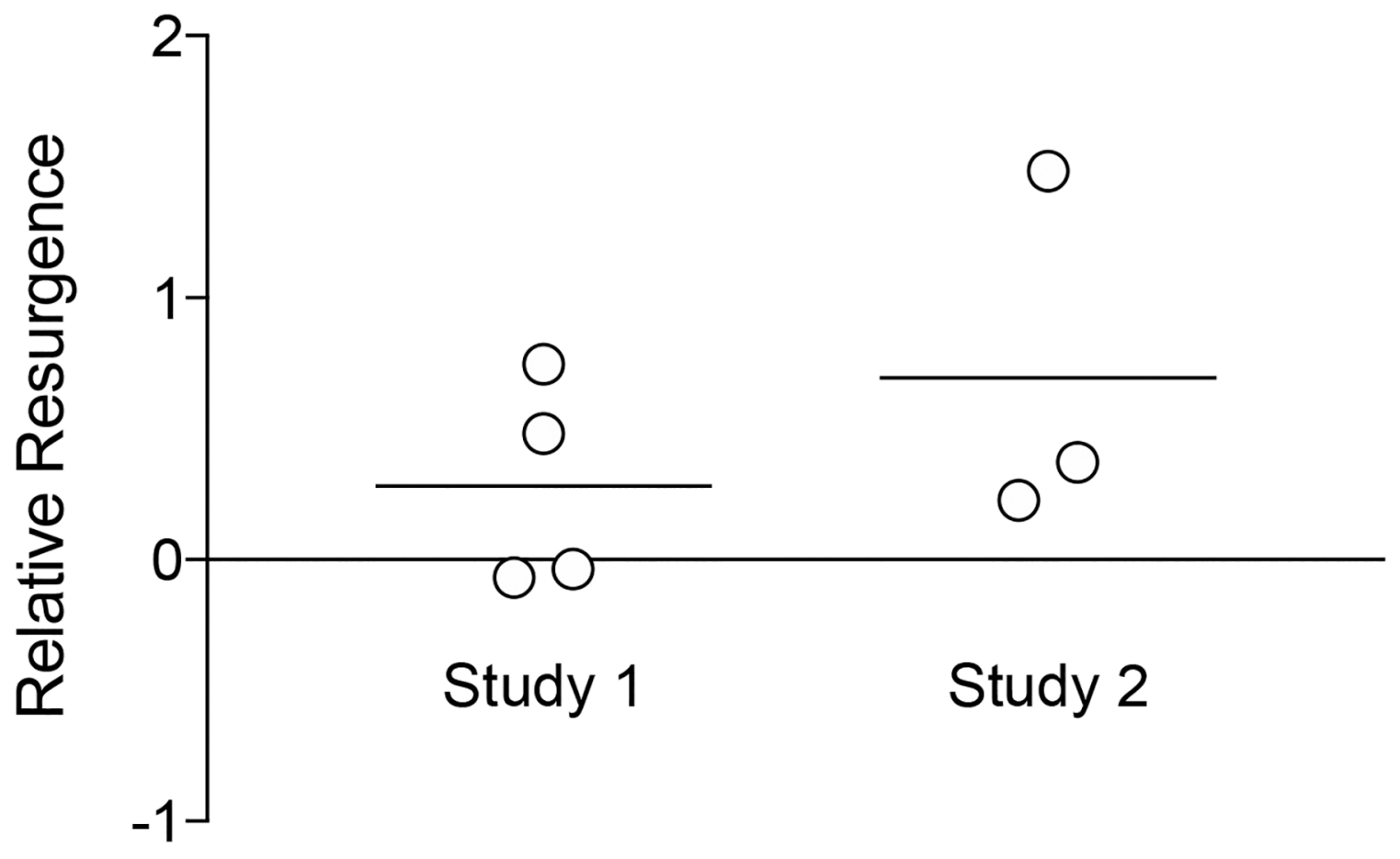

Figure 5.

Relative resurgence of destructive behavior for all participants in Studies 1 and 2. Positive values indicate greater resurgence in the dense baseline condition. 


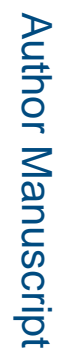

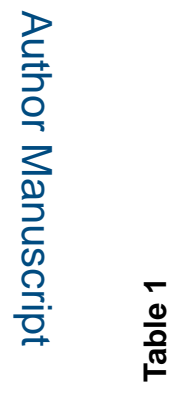

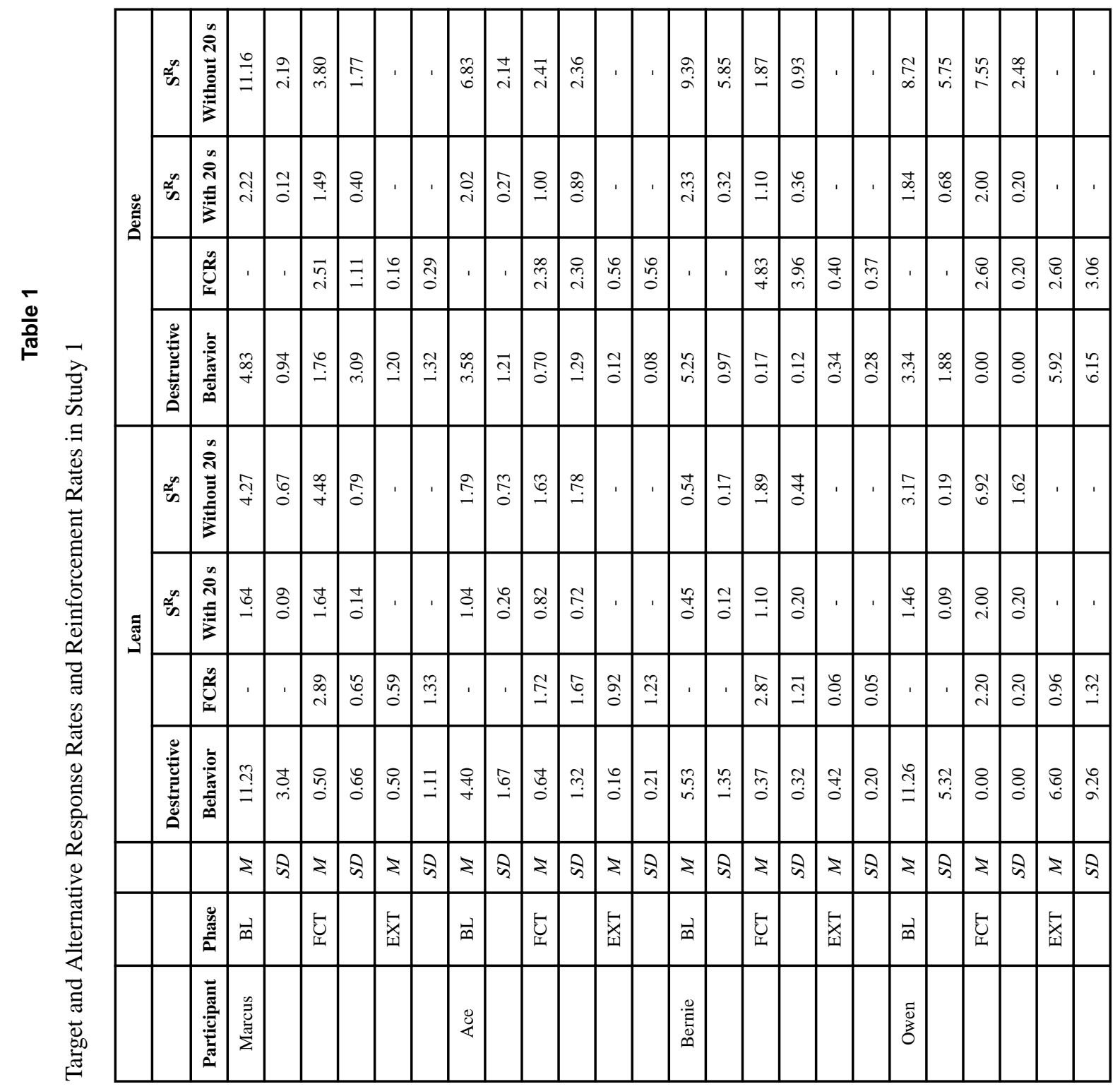

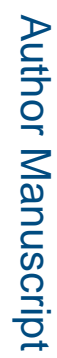

JExp Anal Behav. Author manuscript; available in PMC 2019 January 29. 


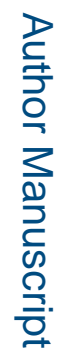

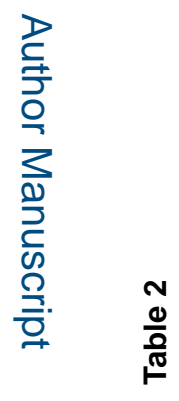

\begin{tabular}{|c|c|c|c|c|c|c|c|c|c|c|c|c|c|c|c|c|c|c|c|c|c|}
\hline & & $\approx^{\infty}$ & 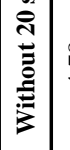 & $\stackrel{\infty}{\stackrel{\infty}{\sim}}$ & ले & \begin{tabular}{|l|}
\multirow{2}{*}{} \\
$\dot{\sigma}$
\end{tabular} & $\stackrel{\overbrace{}}{\pi}$ & ' & . & $\begin{array}{l}\infty \\
\stackrel{\infty}{+} \\
\dot{+}\end{array}$ & $\underset{+}{\stackrel{f}{+}}$ & $\begin{array}{l}\hat{\hat{\theta}} \\
\underline{6}\end{array}$ & $\vec{r}$ & & & $\begin{array}{l}\vec{\infty} \\
i\end{array}$ & $\stackrel{\infty}{\rightarrow}$ & 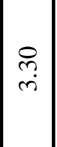 & $\stackrel{\Omega}{2}$ & & \\
\hline & $\begin{array}{l}\ddot{D} \\
\stackrel{0}{0}\end{array}$ & $\approx$ & $\begin{array}{c}0 \\
\tilde{N} \\
\vdots \\
\vdots \\
z\end{array}$ & $\stackrel{尺}{=}$ & $\overline{\vec{o}}$ & $\stackrel{ \pm}{\leftrightarrows}$ & 每 & ' & ' & $\stackrel{ \pm}{ \pm}$ & & $\mid \begin{array}{c}0 \\
i \\
i\end{array}$ & $\stackrel{\circ}{0}$ & & & $\stackrel{\text { I̊ }}{\rightarrow}$ & के & $\stackrel{q}{-}$ & fof & & \\
\hline & & & $\underset{\tilde{z}}{\tilde{I}}$ & ' & ' & $\mid \overrightarrow{\hat{i}}$ & $\tilde{\partial}$ & ঃ̊ & $\stackrel{\bullet}{\circ}$ & ' & ' & $\stackrel{\sim}{m}$ & $\mid \begin{array}{c}\vec{\infty} \\
\dot{0} \\
\dot{0}\end{array}$ & i & $\stackrel{\tilde{r}}{\tilde{r}}$ & & . & $\stackrel{尺}{\stackrel{E}{*}}$ & tr & $\stackrel{q}{\rightarrow}$ & on \\
\hline 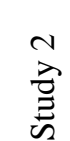 & & 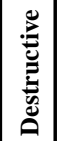 & $\mid$ & $\underset{i}{\stackrel{+}{i}}$ & $\begin{array}{l}\infty \\
\vdots \\
0 \\
0\end{array}$ & 吕 & $\stackrel{\sim}{\dddot{0}}$ & : & $\stackrel{7}{\mathcal{f}}$ & $\stackrel{\beta}{-}$ & $\stackrel{+}{=}$ & $\begin{array}{l}\infty \\
0 \\
0\end{array}$ & $\frac{\infty}{0}$ & $\begin{array}{l}\infty \\
\infty \\
0\end{array}$ & $\stackrel{R}{i}$ & 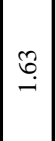 & กิ & o. & $\stackrel{0}{\circ}$ & $\hat{n}$ & f \\
\hline 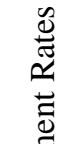 & & $w^{\infty}$ & 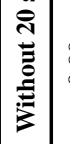 & $\stackrel{\partial}{\partial}$ & $\stackrel{े}{0}$ & 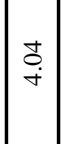 & gr & ' & ' & $\hat{\hat{\sigma}}$ & $\stackrel{\vec{b}}{0}$ & $\begin{array}{l}\hat{a} \\
\mathrm{~d}\end{array}$ & $\stackrel{\circ}{\infty}$ & & & oे & के. & $\begin{array}{l}\bar{\infty} \\
\stackrel{i}{i}\end{array}$ & مُ & & \\
\hline $\begin{array}{l}0.0 \\
\stackrel{0}{0} \\
\stackrel{\Xi}{0}\end{array}$ & ฐ్ & $\tilde{w}^{\infty}$ & 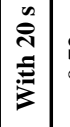 & $\stackrel{N}{0}$ & $\stackrel{0}{0}$ & $\stackrel{\sqrt{3}}{2}$ & I & ' & . & n̂. & $\hat{\tilde{m}}$ & $\bar{a}$ & $\stackrel{s}{\rightarrow}$ & & & ñ & $\underset{d}{0}$ & ঙำ & ले & & \\
\hline $\overrightarrow{\tilde{\Xi}}$ & & & 芯 & . & . & $\mid \begin{array}{l}0 \\
n \\
i \\
i\end{array}$ & $\stackrel{?}{=}$ & 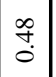 & $\stackrel{\infty}{0}$ & ' & ' & 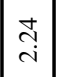 & $\stackrel{\sim}{-}$ & $\mid \begin{array}{c}0 \\
\text { in } \\
\text { n. }\end{array}$ & $\stackrel{\overbrace{}}{i}$ & , & . & $\stackrel{n}{\rightarrow}$ & $\stackrel{8}{0}$ & $\stackrel{8}{-}$ & ? \\
\hline $\begin{array}{l}\tilde{\sim} \\
0 \\
\mathscr{0} \\
\tilde{D} \\
\tilde{\delta}\end{array}$ & & | & 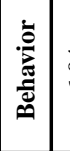 & ț & $\stackrel{+}{\vec{m}}$ & in & f. & $\begin{array}{c}\infty \\
\stackrel{\infty}{0} \\
\infty\end{array}$ & $\begin{array}{l}\text { ț } \\
0\end{array}$ & \begin{tabular}{|l|}
$\infty$ \\
$\stackrel{\sim}{m}$ \\
\end{tabular} & $\underset{\sim}{\stackrel{\infty}{r}}$ & \begin{tabular}{|l|} 
\\
0 \\
0
\end{tabular} & oे & $\stackrel{8}{\circ}$ & $\stackrel{8}{0}$ & $\begin{array}{l}q \\
\text { i } \\
\text { in }\end{array}$ & $\stackrel{\overbrace{}}{\longrightarrow}$ & $\stackrel{?}{0}$ & ড̇ & $\hat{3}$ & $\stackrel{\overbrace{}}{3}$ \\
\hline$\frac{12}{8}$ & & & & $z$ & की & $z$ & की & $z$ & की & $z$ & की & $z$ & की & $z$ & की & $z$ & के & $z$ & की & $\Sigma$ & की \\
\hline 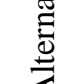 & & & $\begin{array}{l}\mathscr{\mathscr { L }} \\
\stackrel{\mathscr{E}}{E}\end{array}$ & $\vec{\infty}$ & & $\vec{t}$ & & 畜 & & $\vec{\infty}$ & & $\vec{v}$ & & \begin{tabular}{|l} 
畜 \\
\end{tabular} & & $\vec{\infty}$ & & t) & & 畜 & \\
\hline $\begin{array}{l}\vec{\Xi} \\
\vec{\Xi} \\
\vec{\Delta} \\
\overrightarrow{0} \\
\vec{J}\end{array}$ & & & 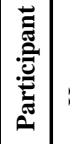 & 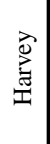 & & & & & & 墕 & & & & & & 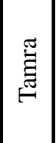 & & & & & \\
\hline
\end{tabular}

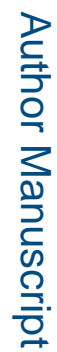

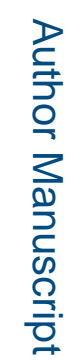

J Exp Anal Behav. Author manuscript; available in PMC 2019 January 29. 